\title{
Specialization in Athletic Training: A Natural Evolution
}

\author{
JJ Wetherington, MS, ATC, OTC
}

St. Luke's Sports Medicine, Boise, ID

\section{Key Phrases}

Emerging settings, organizational and personal outcomes, public health, residency, advanced practice

\section{Correspondence}

Mr. JJ Wetherington, St. Luke's Sports Medicine, 600 Robbins

Road Suite 401, Boise, ID 83709

E-mail: jiwetherington@gmail.com

Twitter: @JJ_ATC

\section{Full Citation}

Wetherington J. Specialization in athletic training: A natural evolution. Clin Pract Athl Train. 2018;1(1):33-36.

https://doi.org/10.31622/2018/0001.7

Submitted: May 4, 2018 Accepted: May 29, 2018

\section{COMMENTARY}

The skill set of the athletic trainer, like the skills of other allied health professionals, has evolved to match the changing demands of patient populations. As the skill set of the athletic trainer has grown, so has the settings that this skill set has been utilized. No longer are athletic trainers only recognizable in the interscholastic and professional sports arenas. The value of the athletic trainers' skillset has resulted in the proliferation of the profession into settings such as physician practice, industrial, public safety, military, and research. As the practice of athletic training has evolved to meet these growing workplace demands, some individuals have developed specialized skills and knowledge that has allowed them to thrive in these emerging settings.

Specialization was first recognized by Adam Smith and immortalized in his seminal publication The Wealth of Nations.' As with the labor sector, specialization in medicine has characterized progression for nearly two decades. ${ }^{2}$ The catalyst for specialization in medicine can be traced to the publication of the, 1910 Flexner Report. After this report healthcare delivery, specifically medical education, radically changed. ${ }^{3}$ Flexner's call for educational reform emphasized more research/evidence-based education and advocated for the pursuit of greater knowledge. ${ }^{3}$ As practitioners devoted their intellectual endeavors to furthering their understanding about increasingly narrower topics, practitioners started to differentiate themselves into specific areas of expertise or focus which led them to dedicate their time in training to those specific areas. ${ }^{2}$ The first medical specialty to create its own assessment board was ophthalmology in 1917.2 In 1933, the four specialties of dermatology, obstetrics and gynecology, otolaryngology, and ophthalmology created a federation called the American Board of Medical Specialties (ABMS). Because of the emergence of these specialties, a national system of standards was created for recognizing specialists and providing information to the public. By 1970, there were 20 specialties. With the most recent addition of Genetics and Genomics in 1991; there are currently 24 specialties recognized by the ABMS. ${ }^{4}$ Specialization is not exclusive to physicians, but also evolved in physical therapy, occupational therapy, and nursing. No matter the profession, specialization in medicine is driven primarily by 3 factors: innovation in medical science and technology, professional preferences, and economic considerations. ${ }^{5}$

\section{Education}

Innovation in medicine is correlated to increasing knowledge about a particular field. ${ }^{6}$ As knowledge increases, advancements in technology inevitably follow, which leads to more complex technological skills and intellectual competencies among practitioners. 6 Increases in knowledge place new and major burdens on professionallevel preparation which can neither teach all the new information, nor quickly revise curricula to exclude the outdated information. ${ }^{6}$ To ensure that all this new knowledge is included, professional programs must sacrifice depth. What results is a generalist preparation, which often requires those passionate few who choose to devote their intellectual energies to understanding specific areas of this new knowledge base to seek postprofessional education to develop specialized expertise.

The profession of athletic training, similar to other professions in medicine, has struggled to balance 
and evolve educational system to meet the growing knowledge base in our field. Athletic training education and accreditation of athletic training programs progressed from being controlled by the member organization of the National Athletic Trainers' Association (NATA) to being independently run by the Commission on Accreditation of Athletic Training Education (CAATE). Along with structural changes, the way that education was delivered has radically changed over that period. ${ }^{7}$ Athletic training evolved from an internship driven-model to a curriculum-driven model. Most recently, the CAATE announced that by 2022 professional programs must transition to the master's level. The educational elevation has inspired an expansion in the breadth of the practice of athletic training. Expanding education is truly the only way to widen scope and demonstrate in a practice analysis that this new knowledge base includes the responsibilities required of the profession. A worry of some surrounding the change in professional degree requirements is that the education for athletic training is becoming too watered down and athletic trainers are lacking depth in their entry-level knowledge base. This is a common worry amongst the athletic training community and is also a concern for other medical professions. For example, this was also a fear of general practitioners, as their knowledge base has widened considerably since its creation. As more and more athletic trainers advance their practice into new and narrower fields, the knowledge base that athletic trainers are expected to know is reaching a critical mass. This increase in knowledge base is placing an increased burden on athletic training educators to teach all the new knowledge without sacrificing depth. As educators spend the majority of their time in the classroom with students teaching the expanding scope of practice, there is even less time for them to clinically practice and evolve their own skills. The lack of time for educators makes it even more difficult for them to teach and provide meaningful experience-based mentorship for their students. This tipping point has happened in other professions and resulted in the creation of formalized specialist training to further clinical skill sets.

Along with the athletic training educational requirements changing, so is the practice of

Copyright (C) by Indiana State University

All rights reserved. ISSN Online 2577-8188 athletic training. Athletic trainers are not only increasing their knowledge base and clinical practice skill set, they have expanded their footprint into settings outside of the interscholastic and professional sports arenas. This expansion of practice into new arenas has required athletic trainers to deepen their current skill set, as well as develop new skills. These new skills are not transferrable to all athletic training practice. Residencies organically developed to meet the need for athletic trainers to deepen their current skills, and learn new skills to help them thrive. The residency model is well known in medicine and is intended to build upon the generalist education that all receive. The $\mathrm{CAATE}$, recognizing the growing trend in specialized training, developed standards for residency programs to ensure that students were receiving advanced preparation through a planned program of clinical and didactic education in specialized content areas. The CAATE has initially recognized eight specialty areas: prevention \& wellness, urgent \& emergent care, primary care, orthopedics, rehabilitation, behavioral health, pediatrics, and performance enhancement. 7 The CAATE has acknowledged that this list is not all encompassing, and has laid out steps to propose new specialties areas as they arise. These are all great steps for ouf the profession that will continue to help the profession advance.

Specializations may narrow even further, or occur when specialties are combined to develop subspecialties (e.g., pediatric neurology). ${ }^{6}$ As subspecialties develop, so will the need for training through fellowships training. The fellowship is seen in medicine, and is intended to deepen a practitioner's focus on a specific topic to the level of content expert. Athletic training has not reached this point yet, but it is not too far off in the future. Similar to physicians, athletic trainers are starting to subspecialize by patient population or body part. In orthopedics alone there are athletic trainers who have subspecialized their practice to pediatrics, trauma, total joint and adult reconstruction, foot and ankle, spine, hand, and/or upper extremity. These ground breaking athletic trainers will be the ones to foster the growth of fellowship training in the field of athletic training.

\section{Professional Practice}


Specialization is an organic evolution of medical practice, but specialized practitioners cannot reach their full potential without support and backing from the profession. As the few innovative professionals devise and test these advanced skills, the profession must perfect who should be utilizing these skills. ${ }^{6}$ Not all of these advanced skills can be performed by all practitioners, and in these cases specialization is often needed to support these particular practices. ${ }^{6}$ The idea of specialization is not always meet with resounding support. Athletic training is no different than other medical professionals who have worried about fragmentation of their profession and the loss or under valuing of the generalist skillset. ${ }^{2}$ Physicians had these same concerns, and specialization was seen as a benefit for the generalist practice, as it allowed for the strengthening, focusing, and reinvestment of the generalist practice and education.

Another concern of specialization is the misrepresentation of unqualified practitioners. ${ }^{2}$ The creation of board certification of specialty status was seen as an ingenious way for professions to control the concerns of specialization. In response to the growth of optometry as a separate discipline, the American Medical Association, and the American Ophthalmological Society created an independent board of specialists. This board was tasked with creating standards that would recognize physicians whose knowledge and skills demonstrated expertise in identifying and treating disorders of the eye. ${ }^{2}$ Physicians created the $A M B S$ as an independent board to maintain the standards for physician certification. ${ }^{4}$ Proposals for new specialties initially come from professional societies and are exhaustively vetted by the board. ${ }^{2}$ The profession of athletic training should follow this blueprint by creating an independent board of specialties who does-not seek to create specialties, but instead focus on the maintenance of quality for the specialty certification. The creation of the specialty certification should come from the specialty practice societies who can properly recognize the specific patient populations, the highly focused knowledge required to treat such patients, and the skills that need to be obtained beyond that of the generalist practice for that specialty field of practice. In addition, these specialty societies

Copyright ( $)$ by Indiana State University All rights reserved. ISSN Online 2577-8188 should determine the qualifications required to sit for the certification examination.

Specialization does not end with satisfactory performance on a single examination. Practitioners need to remain competent throughout their careers. The practice of athletic training has evolved significantly in a short amount of time, and for some athletic trainers this is within the life of their whole career. It has been demonstrated that skills decay and innovation happens, so once a specialty certification is obtained it needs to be maintained. ${ }^{2}$ Recertification requirements are just as vital to the success of the specialty development as initial certification. ${ }^{2}$

\section{Economic Considerations}

In the age of healthcare delivery changes and quality movement, consumers are demanding more from health care. Consumers as well as healthcare organizations are demanding more transparency and higher standards to ensure their providers have the knowledge and skills required for positive patient outcomes. ${ }^{2}$ Board certifications of specialty training is one of the frequent criteria used to ensure competence. ${ }^{2}$ When the public identifies an area of need or an aspirational goal develops, new areas of specialization tend to arise. ${ }^{6}$ Initially these new fields usually have a great shortage of professionals who have both the interest and the specific expertise to address to these problems. ${ }^{6}$ As known from the law of supply and demand, as the supply decreases the demand and cost of the product goes up. Even without specialty certification, the economic benefit of specialty skill set has already being seen. Research has demonstrated that athletic trainers who report performing seven or more specialized skills indicated that they earn significantly higher yearly salaries than those who did not. ${ }^{8}$ However, a proliferation of specialties without adequate reasoning may confuse the public and healthcare organizations, thus minimizing the positive impact of the profession. The value of specialty certification should be undeniable, but most people do not understand what criteria that certification represents, or fully appreciate that different kinds of organizations can offer certificates that represent varying degrees of rigor and clinical relevance. 


\section{Conclusions}

Specialization should be difficult to obtain and just as hard to maintain. It is not meant to degrade or diminish the work of the generalist practitioner. It is, in fact, the recognition that within a generalist discipline it is becoming increasingly difficult to keep up with the depth of knowledge needed for this type of practice, especially when including technical, clinical, and managerial skills. The intended goal of specialization is to promote and foster the growth of the profession. Specialization is not something to be feared. It is something that should be embraced and cultivated. If properly done it can be a huge step forward in the evolution of athletic training. If poorly managed it could mean even more stagnation as the profession is presented with the changing landscape of healthcare delivery.

\section{REFERENCES}

1. Smith A. Inquiry into the Nature and Causes of the Wealth of Nations. London: W. Strahan and T. Cadell; 1776.

2. Cassel CK, Reuben DB. Specialization, subspecialization, and subsubspecialization in internal medicine. New Engl J Med. $2011 ; 364(12): 1169-1173$. https://doi.org/10.1056/NEJMsb 1012647

3. Flexner A. Medical Education in the United States and Canada: A Report to the Carnegie Foundation for the Advancement of Teaching. Bulletin no.4. New York: Carnegie Foundation for the Advancement of Teaching, 1910.

4. ABMS History of Improving Quality Care. American Board of Medical Specialties Web site. http://www.abms.org/aboutabms/history/. Accessed April 16, 2018.

5. Detsky AS, Gauthier SR, Fuchs VR. Specialization in medicine: How much is appropriate. J Am Med Assoc. 2012;307(5):463-464. https://doi.org/10.1001/iama.2012.44

6. Peplau H. Specialization in professional nursing. Clin Nurse Spec. 2003;17(1):3-9. https://doi.org/10.1097/00002800200301000-00002

7. Residency Programs. Commission on Accreditation of Athletic Training Education
Web site. https://caate.net/residencyprograms/. Accessed April 16, 2018.

8. Hassell J, Wetherington J, Kitano J, Scharer $K$, Paturzo $M$. The roles and responsibilities of athletic trainers working the physician practice. Poster session presented at: Big Sky Athletic Training Sports Medicine Conference; 2018; Big Sky, Montana.
Clinical Practice in Athletic Training Volume 1 - Issue 1 - June 2018 